\title{
Polymorphism of the Uteroglobin Gene in Systemic Lupus Erythematosus and IgA Nephropathy
}

\author{
Elisa Menegatti, Antonella Nardacchione, Mirella Alpa, Cecilia Agnes, Daniela Rossi, \\ Marica Chiara, Vittorio Modena, Luigi M. Sena, and Dario Roccatello \\ Dipartimento di Medicina e Oncologia Sperimentale (EM, AN, MA, CA, MC, LMS, D. Roccatello), Cattedre di \\ Patologia Clinica, Università di Torino; Centro di Immunopatologia e Documentazione su Malattie Rare (CMID) (EM, \\ MA, DR, DR) Ospedale Luigi Einaudi; Divisione di Reumatologia (CA, VM), Ospedale S. Giovanni Battista e della \\ Città di Torino, Torino, Italy
}

SUMMARY: Uteroglobin (UG) is a multifunctional protein with anti-inflammatory/immunomodulatory properties. The UG gene is located on the long arm of chromosome 11 (11q12.3-q13.1) in a region linked to some immune disorders. A guanine-adenine substitution at position 38 (A38G) has been found in the noncoding region of exon 1 that is significantly correlated with an increased risk of developing immune-mediated diseases. Recently an experimental model of UG knockout mice showed that in mice, UG deficiency causes severe glomerulopathy with mesangial deposition of IgA-fibronectin complexes. To detect the presence of polymorphisms in the UG coding sequence, the DNA of 109 patients with IgA nephropathy (IgAN), and 32 patients with systemic lupus erythematosus (SLE) were tested for the nucleotide sequence of all three UG exons by heteroduplex analysis. We detected heterozygous DNA only for exon 1 due to the A38G substitution, as confirmed by sequencing. We tested for A38G polymorphism, by restriction endonuclease digestion (Sau96I), both in SLE patients and in IgAN patients. Twenty patients with either membranous nephropathy (12) or focal and segmental glomerular sclerosis and 120 healthy subjects served as controls. Compared with both healthy controls and non-IgA control patients, the frequency of the 38A allele was significantly higher in SLE patients (38 of 64 alleles versus 89 of 240 alleles, $p=0.002$, and versus 7 of 40 alleles, $p<0.001$ ). IgAN patients showed an allelic distribution similar to both control groups. A subgroup of $18 \mathrm{IgAN}$ patients undergoing renal replacement therapy because of end-stage renal disease showed a significant increase in 38A allele frequency ( 5 of $3638 \mathrm{G}$ alleles versus 31 of $3638 \mathrm{~A}$ alleles, $p<0.001$ ). UG is an immunomodulatory agent that is able to (a) inhibit the activity of several phospholipase A2 (PLA2s), (b) interfere with the function of both neutrophils and monocytes, and (c) prevent immune recognition, perhaps by masking surface antigens. This could account for the role this molecule plays in SLE. The A38G polymorphism is located within a region corresponding to the rat minimal promoter that proved to be important in the transcriptional regulation of UG. Although the significance of any alterations in the UG exon 1 noncoding region in humans has yet to be clarified, initial evidence suggests that it may alter the control of immune response and of inflammation. (Lab Invest 2002, 82:543-546).

$U$ teroglobin (UG) is a multifunctional protein that was first discovered in rabbit uterus (Krishnan and Daniel, 1967). To date, UG expression has been found in many other organs sharing endocrine and exocrine functions (including thymus, pituitary gland, respiratory and gastrointestinal tracts, pancreas, mammary gland, prostate, and seminal vesicles; (Peri et al, 1993) and has been detected in the blood (Kikukawa and Mukherjee, 1989) and urine (Jackson et al, 1988). Thus, UG is produced in the secretory epithelia that communicate with the external environment. $U G$ is not synthesized in the kidney, but is recognized by mesangial cell receptors. It is a dimer with a molecular mass of $16 \mathrm{kd}$, but, due to the anomalous electrophoretic mobility, it migrates like a $10-k d$ protein in polyacrylamide gel electrophoresis. Thus, UG is also known as a 10-kd protein produced

Received October 3, 2001.

Address reprint requests to: Dr. Dario Roccatello, Centro di Immunopatologia e Documentazione su Malattie Rare (CMID), Ospedale Luigi Einaudi, Via Cigna 74, 10152, Torino, Italy.E-mail: cmid@iol.it by Clara cells (Singh et al, 1988), that is, the cells lining the bronchiolar epithelium.

Several other names have been coined to define this protein with immunomodulatory and anti-inflammatory properties. An essential role-as determined in UG-null mice (Zheng et al, 1999)_-seems to be the prevention of abnormal glomerular deposition of multimeric fibronectin and collagen. Furthermore, UG inhibits both monocyte and neutrophil chemotaxis and phagocytosis (Schiffmann et al, 1983), reduces antigenicity of foreign proteins by masking surface antigens (Siiteri et al, 1977) and contains potent phospholipase $\mathrm{A}_{2}\left(\mathrm{PLA}_{2}\right)$-inhibitory effects in the 39 to 47 sequence of the $\alpha$ helix 3 (Levin et al, 1986). Inhibition of PLA 2 activity limits the metabolization of arachidonic acid and the synthesis of prostaglandin and leukotriene mediators, which have been implicated in the pathogenesis of glomerular diseases (Menegatti et al, 1999).

UG is encoded by a single-copy gene of $3 \mathrm{~kb}$ and comprises 3 exons (118, 187, and 135 bp), 2 introns, and a $550 \mathrm{bp}$-untranslated region in the 5 '-prime end. The UG gene is located on the long arm of chromosome 11 (11q12.3-q13.1), within a region linked to 
some immune-mediated disorders, including atopy and increased airway responsiveness (Daniels et al, 1996; van Herwerden et al, 1995). A microsatellite marker has been identified within the 190-bp region of intron 1 and a polymorphic Alu insert was found in intron 2, but neither of the two polymorphic regions seems to affect splicing of the UG mRNA transcript (Hay et al, 1995). Recently, mutation detection methods identified an adenine to guanine substitution in the UG gene at position 38, downstream from the transcription initiation site (within the noncoding region of exon 1), which was associated with an increased risk of asthma (Laing et al, 1998).

More recently, studies on UG gene polymorphism were specifically addressed in $\operatorname{lgA}$ nephropathy (IgAN) patients (Szelestei et al, 2000; Kim et al, 2001) after Zheng's report that two independent UG-deficient mouse models developed pathologic findings resembling those of human IgAN, including glomerular accumulation of IgA (Zheng et al, 1999). Human studies produced conflicting results: whereas one study (Szelestei et al, 2000) showed that the GG genotype of the G38A UG polymorphism was more common than $A G+A A$ genotypes in patients with progressive disease, another report (Kim et al, 2001) showed that the risk of disease progression increased as the number of $A$ alleles increased. IgAN is a relatively common glomerular disease with slow progression in a conspicuous number of patients. The definition of progressive cases can be established only over several years due to the irregular clinical course characterized by phases of accelerated decrease in renal function, often combined with prolonged phases of clinical stabilization. The unequivocal definition of $\lg A N$ with worse clinical course implies isolating patients undergoing replacement of renal function with dialysis or transplantation. These cases were missing in both the previous studies. Moreover, for the first time, the present report also focuses on patients with systemic lupus erythematosus (SLE), because UG interferes in many ways with the physiological machinery of immune recognition.

\section{Results}

Results of allele distribution confirmed previous data showing 38G to be the most common allele in the normal population. Compared both with the 120 healthy and with the 20 diseased controls, 38A allele frequency was found to be significantly higher in the 32 SLE patients $(p=0.002)$ (Table 1$)$.
In the $109 \lg \mathrm{AN}$ patients, 38A and 38G allele frequencies and genotype distribution were not significantly different from both control groups (Table 1). Neither the extent of urinary abnormalities nor histologic features (scored according to Emancipator's classification; Emancipator, 1992) were related to UG polymorphism. However, the subgroup of $18 \operatorname{lgAN}$ patients who progressed to end-stage renal disease showed a significant increase in $38 \mathrm{~A}$ allele frequency (5 of $3638 \mathrm{G}$ alleles versus 31 of $3638 \mathrm{~A}$ alleles, $p<$ $0.001)$

\section{Discussion}

Current views on the pathogenesis of IgAN definitely suggest a mechanism of altered glycosylation of patient IgA molecule. Hypogalactosylated IgA escapes the hepatic asyaloglycoprotein receptor removal system, has prolonged circulation in the blood stream, tends to self-aggregate and aggregate with IgG, and binds to normal components of the mesangial matrix (Roccatello et al, 1993).

An attractive hypothesis is that these phenomena may be favored by functionally impaired UG, because an abnormal glomerular deposition of fibronectin and collagen combined with $\lg A$ was observed in models of transgenic knockout mice. Present data do not support the global overall involvement of UG A38G polymorphism in IgAN. However, IgAN is a microcosm of glomerular lesions with a wide variety of possible clinical courses ranging from asymptomatic hematuria, to indolent slow progression, to rapid evolution toward end-stage renal disease. The strong association of IgAN with the worst clinical course with the 38A allele sustains the role of the $A 38 G$ polymorphism in this specific subset of patients, making it possible to identify patients who are at risk for developing endstage renal disease.

$U G$ is an anti-inflammatory/immunomodulatory agent that is able to (a) inhibit the activity of several phospholipases A2 (PLA $A_{2}$, E.C. 3.1.1.4), (b) interfere with the function of both neutrophils and monocytes, and (c) prevent immune recognition, perhaps by masking surface antigens. This could account for the role of this molecule in the most typical immunemediated disease, SLE.

The A38G polymorphism is located within a region corresponding to the rat minimal promoter that was identified downstream from region I (that includes a few functional factor-binding sites) and the TATA box, and which was shown to play a key role in the

Table 1. Allele Distribution in Systemic Lupus Erythematosus and IgA Nephropathy Patients and Study Controls

\begin{tabular}{rccccc}
\hline & $\begin{array}{c}\text { Non-end-stage } \\
\text { IgAN Patients }\end{array}$ & $\begin{array}{c}\text { End-stage } \\
\text { IgAN Patients }\end{array}$ & $\begin{array}{c}\text { SLE } \\
\text { Patients }\end{array}$ & $\begin{array}{c}\text { Normal } \\
\text { Controls }\end{array}$ & $\begin{array}{c}\text { Non IgA-GN } \\
\text { Patients }\end{array}$ \\
\hline \multirow{2}{*}{$38 \mathrm{G}$} & $125 / 182$ & $5 / 36$ & $26 / 64$ & $151 / 240$ & $33 / 40$ \\
& $68.7 \%$ & $13.9 \%$ & $40.7 \%$ & $62.9 \%$ & $82.5 \%$ \\
$38 \mathrm{~A}$ & $57 / 182$ & $31 / 36$ & $38 / 64$ & $89 / 240$ & $7 / 40$ \\
& $31.3 \%$ & $86.1 \%$ & $59.3 \%$ & $37.1 \%$ & $17.5 \%$ \\
\hline
\end{tabular}

SLE, systemic lupus erythematosus; IgAN, IgA nephropathy. 
transcriptional regulation of the UG promoter. Although the mechanism of the clinical relevance of any alteration to the UG exon 1 noncoding region in humans has yet to be entirely established, initial evidence suggests it might affect the physiologic counteracting mechanisms of inflammation, possibly affecting the UG protein expression as in other models of immune disease (Laing et al, 1998).

\section{Materials and Methods}

To detect the presence of polymorphisms in the UG coding sequence, the three exons of the UG gene were preliminarily screened in a sample of nephropathic patients. Genomic DNA was isolated from the total blood of 202 patients with various glomerular disorders. Patients included 30 women and 2 men with SLE, 31 women and 78 men with IgA mesangial nephropathy (IgAN), and 20 patients (9 women and 11 men) with membranous nephropathy (MN) or Focal and segmental glomerular sclerosis (FSGS) who represented the diseased control group; 120 healthy blood donors (57 women and 63 men) served as normal controls. SLE was diagnosed on clinical and serological grounds. Thirteen of 32 cases were also studied with renal biopsy, because of urinary abnormalities and decreased renal function. Each patient fulfilled the revised American Rheumatism Association criteria in the diagnosis of SLE (Tan et al, 1982). Systemic signs were prospectively identified and blindly evaluated by two observers (DRos and DRoc). Diagnoses of IgAN, MN, and FSGS were assessed by renal biopsy. Forty-seven patients had normal-renal function with a mean creatinine clearance of $113.14 \pm$ $19 \mathrm{ml}$ per minute per $1.73 \mathrm{~m}^{2}$ (range, $78-162 \mathrm{ml}$ per minute per $\left.1.73 \mathrm{~m}^{2}\right)$, and mean proteinuria was $1.72 \pm$ $0.83 \mathrm{~g}$ per day (range 1-3.5 g per day). Eighteen of 109 IgAN patients (4 women and 14 men) progressed to end-stage renal disease.

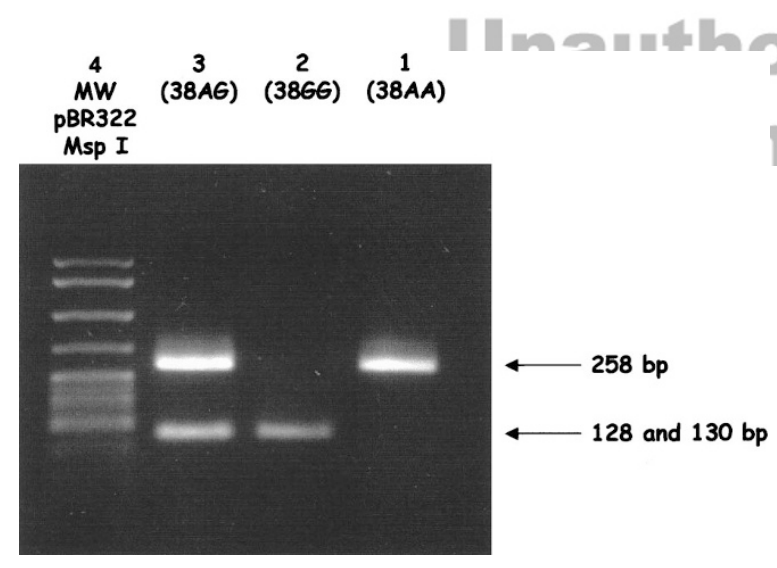

Figure 1.

Restriction digestion of DNA samples showed three alternate digestion patterns identifying heterozygous and homozygous subjects. The 38GG homozygous sample (1) showed a single band due to complete digestion by the Sau96l restriction enzyme in two bands of 128 and 130 bp that migrate together. The 38AA homozygous sample (2) showed a single band of $258 \mathrm{bp}$ due to the absence of the specific Sau96l restriction site. Heterozygous samples (3) showed both bands (258 bp, 128-130 bp).
The three exons were amplified by PCR (exon 1: 5'-CAGTATCTTATGTAGAGCCC-3'; 5'-CCTGAGAGTTCCTAAGTCCAGG-3'; exon 2: 5'-CCTGGAGACATGTGCCTTCT-3'; 5'-GTGTGACGTGAAAGGTGCTG3'; exon 3: 5'-TTGGGTTTTTCTGTTTCTTTGTC-3': 5'-GAGATGCTTGTGGTTTATTGA-3'). Single-strand conformational polymorphism (SSCP; Laing et al, 1998) and heteroduplex analysis were used to detect alterations in the sequence of individual PCR products. Both analyses showed a variation between individual migration patterns for exon 1 alone. DNA samples presenting band shifts have been sequenced for exon 1, and an A38G substitution in the noncodifying region of exon 1 detectable by Sau96I endonuclease digestion was identified (Laing et al, 1998).

Thirty-two SLE patients, 109 IgAN patients, 20 control patients with non-IgA and non-lupus-associated glomerulopathies, and 120 healthy controls were examined by Sau96I endonuclease restriction analysis (Fig. 1). Digested DNA samples were examined on products subjected to electrophoresis on a $2 \%$ agarose gel containing ethidium bromide $(1.5 \mu \mathrm{g} / \mathrm{ml})$.

\section{Statistics}

The $\chi^{2}$ test was used to analyze allele frequency distribution.

\section{References}

Daniels SE, Bhattacharrya S, James A, Leaves NI, Young A, Hill MR, Faux JA, Ryan GF, Le Souef PN, Lathrop GM, Musk AW, and Cookson WO (1996). A genome-wide search for quantitative trait loci underlying asthma. Nature 383:247250.

Emancipator SN (1992). Primary and secondary forms of IgA nephritis. In: Heptinstall $\mathrm{RH}$, editor. Pathology of the kidney. Boston: Little Brown and Co., 389-476.

Hay JG, Danel C, Chu CS, and Crystal RG (1995). Human CC10 gene expression in airway epithelium and subchromosomal locus suggest linkage to airway disease. Am J Physiol 268:L565-575

Jackson PJ, Turner R, Keen JN, Brooksbank RA, and Cooper EH (1988). Purification and partial amino acid sequence of human urine protein 1. Evidence for homology with rabbit uteroglobin. J Chromatogr 452:359-367.

Kikukawa T and Mukherjee AB (1989). Detection of a uteroglobin- like phospholipase A2 inhibitory protein in the circulation of rabbits. Mol Cell Endocrinol 62:177-187.

Kim TS, Kang D, Kwon DY, Park W-Y, Kim H, Lee D-S, Lim CS, Han JS, Kim S, and Lee JS (2001). Uteroglobin gene polymorphisms affect the progression of immunoglobulin Anephropathy by modulating the level of uteroglobin expression. Pharmacogenetics 11:299-305.

Krishnan RS and Daniel JC Jr (1967). "Blastokinin": Inducer and regulator of blastocyst development in the rabbit uterus. Science 158:490-492.

Laing IA, Goldblatt J, Eber E, Hayden CM, Rye PJ, Gibson NA, Palmer LJ, Burton PR, and Le Souëf PN (1998). A polymorphism of the CC16 gene is associated with an increased risk of asthma. J Med Genet 35:463-467. 
Levin SW, Butler JD, Schumacher UK, Wightman PD, and Mukherjee AB (1986). Uteroglobin inhibits phospholipase A2 activity. Life Sci 38:1813-1819.

Menegatti E, Roccatello D, Fadden K, Piccoli G, De Rosa G, Sena LM, and Rifai A (1999). Gene expression of 5-lipoxygenase and LTA4 hydrolase in renal tissue of nephrotic syndrome patients. Clin Exp Immunol 116:347-353.

Peri A, Cordella-Miele E, Miele L, and Mukherjee AB (1993). Tissue-specific expression of the gene coding for human Clara cell $10 \mathrm{kD}$ protein, a phospholipase A2-inhibitory protein. J Clin Invest 92:2099-2109.

Roccatello D, Picciotto G, Torchio M, Ropolo R, Ferro M, Franceschini R, Quattrocchio G, Cacace G, Coppo R, Sena LM, DeFilippi PG, and Piccoli G (1993). Removal system of immunoglobulin $A$ and immunoglobulin A containing complexes in IgA nephropathy and cirrhosis patients. The role of asyaloglycoprotein receptors. Lab Invest 69:714-723.

Schiffmann E, Geetha V, Pencev D, Warabi H, Mato J, Hirata F, Manjunath R, Mukherjee A, Liotta L, and Terranova VP (1983). Adherence and regulation of leukotaxis. Agents Actions 12(Suppl):106-120.

Siiteri PK, Febres F, Clemens LE, Chang RJ, Gondos B, and Stites D (1977). Progesterone and maintenance of pregnancy: Is progesterone nature's immunosuppressant? Ann NY Acad Sci 286:384-397.
Singh G, Singh J, Katyal SL, Brown WE, Kramps JA, Paradis IL, Dauber JH, Macpherson TA, and Squeglia N (1988). Identification, cellular localization, isolation, and characterization of human Clara cell-specific $10 \mathrm{kD}$ protein. J Histochem Cytochem 36:73-80.

Szelestei T, Bähring S, Kovacs T, Vas T, Salamon C, Busjahn A, Luft FC, and Nagy J (2000). Association of a uteroglobin polymorphism with rate of progression in patients with $\lg \mathrm{A}$ nephropathy. Am J Kidney Dis 36:468-473.

Tan EM, Cohen AS, and Fries JF (1982). The 1982 revised criteria for the classification of systemic lupus erythematosus. Arthritis Rheum 25:1276-1282.

van Herwerden L, Harrap SB, Wong ZYH, Abramson MJ, Kutin J, Forbes A, Raven J, Lanigan A, and Walters E (1995). Linkage of high-affinity IgE receptor gene with bronchial hyperreactivity, even in absence of atopy. Lancet 346:12621265.

Zheng F, Kundu GC, Zhang Z, Ward J, DeMayo F, and Mukherjee $A B$ (1999). Uteroglobin is essential in preventing immunoglobulin A nephropathy in mice. Nat Med 5:10181025.

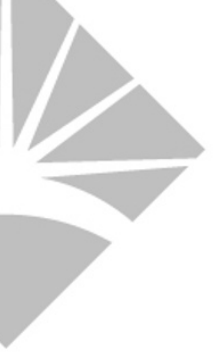

LIPPINCOTT

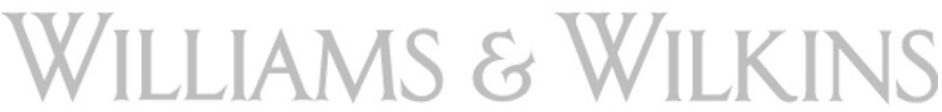

